Pacific Journal of Mathematics

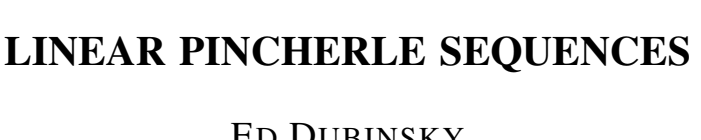




\title{
LINEAR PINCHERLE SEQUENCES
}

\section{ED DUBINSKY}

\begin{abstract}
Dragilev's theory of regular bases in nuclear Fréchet spaces is applied to obtain necessary and sufficient conditions in terms of the zeros for a linear Pincherle sequence to be a basis for the space $\mathscr{F}_{R}$ of functions analytic on the interior of the disk of radius $R \leqq \infty$. It is shown that a linear Pincherle basis is always proper. All possible phenomena for the basis radius of a linear Pincherle sequence are exhibited. In this connection it is shown that for any finite $R_{0}>0$ there is a sequence of analytic functions which is a basis for $\mathscr{F}_{R}$ if and only if $R \leqq R_{0}$ or $R=\infty$.
\end{abstract}

A classical problem of fundamental interest is to study the representability of analytic functions as infinite series in a given sequence of functions. The purpose of this note is to point out one case in which recent developments in the theory of nuclear Fréchet spaces are directly applicable and lead to results which have not been obtained by other methods.

In order to describe the results it is necessary to explain certain concepts. A sequence $\left(\alpha_{n}\right)$ in a Fréchet space $E$ is a basis if each $x \in E$ has a representation $x=\sum c_{n} \alpha_{n}$ where $\left(c_{n}\right)$ is a sequence of scalars uniquely determined by $x$ and the infinite series converges in the topology of $E$. Two bases, $\left(\alpha_{n}\right)$ and $\left(\beta_{n}\right)$ are equivalent if $\sum c_{n} \alpha_{n}$ converges in $E$ if and only if $\sum c_{n} \beta_{n}$ converges in $E$.

Let $0<R \leqq \infty$. We shall be interested in the nuclear Fréchet space $\mathscr{F}_{R}$ consisting of all functions analytic on the open disk of radius $R$, equipped with the topology of uniform convergence on compact sets. As is well known, the sequence $\left(z^{n}\right)$ is a basis for $\mathscr{F}_{R}$. An arbitrary basis, $\left(\alpha_{n}\right)$ for $\mathscr{F}_{R}$ will be called proper if it is equivalent to $\left(z^{n}\right)$.

The general question then can be viewed as the problem of determining when a sequence $\left(\alpha_{n}\right)$ is a basis for $\mathscr{F}_{R}$ and when it is a proper basis. Of course, one can only hope for conclusive results in special cases. M. Arsove, in a series of papers over the past 15 years (see [1] for a bibliography) has considered Pincherle sequences in which $\alpha_{n}$ has the form $\alpha_{n}(z)=z^{n} \psi_{n}(z), n=0,1,2, \cdots$ where each $\psi_{n}$ is a function in $\mathscr{F}_{R}$ and $\psi_{n}(0)=1$. Most recently, in [1], Arsove studied linear Pincherle sequences in which each $\psi_{n}$ is a nonconstant linear function with its zero at $z_{n}$, so we can write,

$$
\alpha_{n}=z^{n}\left(1-\frac{z}{z_{n}}\right), \quad n=0,1,2, \cdots .
$$


Our results can then be described as a complete determination, in terms of the sequence of zeros $\left(z_{n}\right)$, of when a linear Pincherle sequence is a basis and when it is proper. Also we consider the question of how the result depends on the value of $R$. It is hoped that both our results and our method will be useful in studying general Pincherle sequences.

Our method is to apply a deep result of M. M. Dragilev ([3], Theorem 5), which we use in the formulation given by C. Bessaga [2]. In order to describe the method, we must introduce some further concepts. Let $\left(x_{n}\right)$ be a basis for a nuclear Fréchet space $E$. We say that the basis is regular if there is a fundamental sequence of seminorms $\left(\|\cdot\|_{k}\right)$ for $E$ such that

$$
\frac{\left\|x_{n}\right\|_{k}}{\left\|x_{n}\right\|_{k+1}} \geqq \frac{\left\|x_{n+1}\right\|_{k}}{\left\|x_{n+1}\right\|_{k+1}} \quad \text { for all } n \text { and } k .
$$

We say that the basis is of type $D_{1}$ or $D_{2}$ if we have $\left(\|\cdot\|_{k}\right)$ such that (R) is satisfied and

$$
\left\|x_{n}\right\|_{1}=1 \text { for all } n \text { and } \forall k \exists j \ni \sup _{n} \frac{\left\|x_{n}\right\|_{k}^{2}}{\left\|x_{n}\right\|_{j}} \leqq 1
$$

or

$$
\lim _{k}\left\|x_{n}\right\|_{k}=1 \text { for all } n \text { and } \forall k \exists j \ni \sup _{n} \frac{\left\|x_{n}\right\|_{k}}{\left\|x_{n}\right\|_{j}^{2}} \leqq 1 .
$$

Then the main result which we will use in this paper is due to Dragilev and has the following formulation:

Lemma. If $\left(x_{n}\right)$ and $\left(y_{n}\right)$ are regular basis in a nuclear Fréchet space and they are both of type $\mathrm{D}_{1}$ or of type $\mathrm{D}_{2}$ then they are equivalent.

The proof of the lemma is immediate from [2], 1.10 formulas (5) and (6).

Now we explain some of the notation which will be used. For the topology in the space $\mathscr{F}_{R}$, we can take the seminorms $\|\cdot\|_{\rho}$, $0<\rho<R$ given by

$$
\|f\|_{\rho}=\sum_{n=0}^{\infty}\left|c_{n}\right| \rho^{n}, \quad f=\sum_{n=0}^{\infty} c_{n} z^{n} \in \mathscr{F}_{R} .
$$

We set, for $0<R \leqq \infty$,

$$
\Lambda_{R}=\left\{\left(\xi_{n}\right): \exists f \in \mathscr{F}_{R} \ni f(z)=\sum_{n=0}^{\infty} \xi_{n} z^{n},|z|<R\right\} .
$$

As is well known, $\xi \in \Lambda_{R}$ iff $\overline{\lim }\left|\xi_{n}\right|^{1 / n} \leqq 1 / R$. The map $J: \Lambda_{R} \rightarrow \mathscr{F}_{R}$ 
given by

$$
J\left(\left(\xi_{n}\right)\right)=\sum_{n=0}^{\infty} \xi_{n} z^{n}
$$

is an algebraic isomorphism and we write $e^{n}=J^{-1}\left(z^{n}\right)$. We can use $J$ to define a topology on $\Lambda_{R}$ (carried over from $\mathscr{F}_{R}$ ). It is not hard to show that the topology is defined by the seminorms $\|\cdot\|_{\rho}, 0<\rho<R$ where

$$
\left\|\left(\xi_{n}\right)\right\|_{\rho}=\sup _{n}\left|\xi_{n}\right| \rho^{n}, \quad\left(\xi_{n}\right) \in \Lambda_{R} .
$$

Given a linear Pincherle sequence $\left(\alpha_{n}\right)$ with zeros $\left(z_{n}\right)$ and $0<R \leqq \infty$, we will use the labels $p=p(R)$ and $r_{n}=r_{n}(R)$ given by

$$
p=\left\{\begin{array}{l}
1 \text { if } R=\infty \\
R \text { if } R<\infty
\end{array}, \quad r_{n}=\frac{\left|z_{n}\right|}{\left(p+\left|z_{n}\right|\right) p^{n}}, \quad n=0,1,2, \cdots .\right.
$$

The symbol $z_{m} \cdots z_{n-1}$ is clear if $n>m$ and if $n=m$ we will take it to be 1 .

An automorphism is a linear topological isomorphism of a space onto itself. We recall that two bases $\left(x_{n}\right)$ and $\left(y_{n}\right)$ in a Fréchet space $E$ are equivalent iff there is an automorphism $T$ of $E$ such $T x_{n}=y_{n}$. Also, it is obvious that if $\left(x_{n}\right)$ is a basis and $\left(t_{n}\right)$ is a sequence of nonzero scalars, then $\left(t_{n} x_{n}\right)$ is a basis.

Theorem 1. A linear Pincherle sequence $\left(\alpha_{n}\right)$ with zeros $\left(z_{n}\right)$ is a basis for $\mathscr{F}_{R}, 0<R \leqq \infty$ iff

$$
\forall \rho<R \exists \bar{\rho}<R \ni \sup _{n} \sup _{n \geqq m} \frac{\left(1+\left|z_{n}\right|\right) \rho^{n}}{\left|z_{m} \cdots z_{n}\right| \bar{\rho}^{m}}<\infty .
$$

Proof. Suppose that $\left(\alpha_{n}\right)$ is a basis for $\mathscr{F}_{R}$.

The first step is to show that the basis $\left(r_{n} \alpha_{n}\right)$ is of type $\mathrm{D}_{1}$ or $\mathrm{D}_{2}$ according as $R=\infty$ or $R<\infty$. Consider the seminorms on $\mathscr{F}_{R}$ and compute, for $\rho<\bar{\rho}$,

$$
\begin{aligned}
\frac{\left\|\alpha_{n}\right\|_{\rho}\left\|\alpha_{n+1}\right\|_{\bar{\rho}}}{\left\|\alpha_{n}\right\|_{\bar{\rho}}\left\|\alpha_{n+1}\right\|_{\rho}} & =\frac{\left(\rho^{n}+\frac{1}{\left|z_{n}\right|} \rho^{n+1}\right)\left(\bar{\rho}^{n+1}+\frac{1}{\left|z_{n+1}\right|} \bar{\rho}^{n+2}\right)}{\left(\bar{\rho}^{n}+\frac{1}{\left|z_{n}\right|} \bar{\rho}^{n+1}\right)\left(\rho^{n+1}+\frac{1}{\left|z_{n}\right|} \rho^{n+2}\right)} \\
& =\frac{\bar{\rho}\left|z_{n} \| z_{n+1}\right|+\bar{\rho}^{2}\left|z_{n}\right|+\rho \bar{\rho}\left|z_{n+1}\right|+\rho \bar{\rho}^{2}}{\rho\left|z_{n} \| z_{n+1}\right|+\rho^{2}\left|z_{n}\right|+\rho \bar{\rho}\left|z_{n+1}\right|+\rho^{2} \bar{\rho}}>1
\end{aligned}
$$

whence the basis $\left(\alpha_{n}\right)$ is regular, so the basis $\left(r_{n} \alpha_{n}\right)$ is also regular. If $R=\infty$, we have

$$
\left\|r_{n} \alpha_{n}\right\|_{1}=\frac{\left|z_{n}\right|}{1+\left|z_{n}\right|}\left(1+\frac{1}{\left|z_{n}\right|}\right)=1
$$

and, for $1 \leqq \rho^{2} \leqq \bar{\rho}$, 


$$
\frac{\left\|r_{n} \alpha_{n}\right\|_{\rho}^{2}}{\left\|r_{n} \alpha_{n}\right\|_{\bar{\rho}}}=\frac{\left|z_{n}\right|\left(\rho^{n}+\frac{1}{\left|z_{n}\right|} \rho^{n+1}\right)^{2}}{\left(1+\left|z_{n}\right|\right)\left(\bar{\rho}^{n}+\frac{1}{\left|z_{n}\right|} \bar{\rho}^{n+1}\right)} \leqq \frac{\left|z_{n}\right|^{2}+2 \rho\left|z_{n}\right|+\rho^{2}}{\left|z_{n}\right|^{2}+(\bar{\rho}+1)\left|z_{n}\right|+\bar{\rho}} \leqq 1,
$$

so the property $\left(D_{1}\right)$ is satisfied.

If $R<\infty$, we fix $n$ and have

$$
\lim _{\rho \rightarrow R}\left\|r_{n} \alpha_{n}\right\|_{\rho}=\lim _{\rho \rightarrow R} \frac{\rho^{n}\left(\rho+\left|z_{n}\right|\right)}{R^{n}\left(R+\left|z_{n}\right|\right)}=1 .
$$

Also, for $0<\rho<\bar{\rho}^{2} / R$,

$$
\lim _{n \rightarrow \infty} \frac{\left\|r_{n} \alpha_{n}\right\|_{\rho}}{\| r_{n} \alpha_{n} \mid \frac{2}{\rho}}=\lim _{n \rightarrow \infty} \frac{(R \rho)^{n}\left(\rho+\left|z_{n}\right|\right)}{\bar{\rho}^{2 n}\left(\bar{\rho}+\left|z_{n}\right|\right)}=0,
$$

so the property $\left(D_{2}\right)$ is satisfied.

Next we observe that it is a simple matter to check that in $\mathscr{F}_{R}$, the basis $\left(\left(1 / p^{n}\right) z^{n}\right)_{n}$ is also of type $\mathrm{D}_{1}$ or $\mathrm{D}_{2}$ according as $R$ is infinite or finite. Hence it follows from the lemma that the basis $\left(r_{n} \alpha_{n}\right)$ is equivalent in $\mathscr{F}_{R}$ to the basis $\left(\left(1 / p^{n}\right) z^{n}\right)$. This in turn implies that $\left(r_{n} p^{n} \alpha_{n}\right)$ is a proper basis in $\mathscr{F}_{R}$.

Thus we have an automorphism $T: \Lambda_{R} \rightarrow \Lambda_{R}$ given by the relation, $T \xi=\eta$ where $\xi, \eta$ are determined by the relation,

$$
\sum_{n=0}^{\infty} \xi_{n} z^{n}=\sum_{n=0}^{\infty} \eta_{n} r_{n} p^{n} \alpha_{n} .
$$

Using formula (3.3) of [1], we obtain that

$$
T e^{m}=\sum_{n=m}^{\infty} \frac{1}{r_{n} p^{n} z_{m} \cdots z_{n-1}} e^{n}=\sum_{n=m}^{\infty} \frac{p+\left|z_{n}\right|}{z_{m} \cdots z_{n-1}\left|z_{n}\right|} e^{n} .
$$

It is not hard to check, using the seminorms in $\Lambda_{R}$, that the continuity of $T$ is equivalent to the statement,

$$
\forall \rho<R \exists \bar{\rho}<R \ni \sup _{m} \frac{\left\|T e^{m}\right\|_{\rho}}{\mid e^{m} \|_{\rho}}<\infty .
$$

Using the definitions of these seminorms in the explicit representation for $T$, we see that the continuity of $T$ is equivalent to,

$$
\forall \rho<R \exists \bar{\rho}<R \ni \sup _{m} \sup _{n \geqq m} \frac{\left(p+\left|z_{n}\right|\right) \rho^{n}}{\left|z_{m} \cdots z_{n}\right| \bar{\rho}^{m}}<\infty .
$$

When $R=\infty$, this is exactly $\left(C_{\infty}\right)$. For $R<\infty$ this is equivalent to $\left(C_{R}\right)$ in view of the fact that

$$
\min (1, p) \leqq \frac{p+\left|z_{n}\right|}{1+\left|z_{n}\right|} \leqq \max (1, p), \quad 0<p<\infty .
$$


This completes the necessity portion of the proof.

Now suppose that $\left(C_{R}\right)$ holds. We can then immediately assert the existence and continuity of the map $T: \Lambda_{R} \rightarrow \Lambda_{R}$ defined by the relation (1). We can use this relation to compute,

$$
T^{-1} e^{m}=r_{m} p^{m}\left(e^{m}-\frac{1}{z_{m}} e^{m+1}\right) .
$$

This map is in any case continuous because

$$
\sup _{m} \frac{\left\|T^{-1} e^{m}\right\|_{\rho}}{\left\|e^{m}\right\|_{\rho}}=\sup _{m} \max \left\{\frac{\left|z_{m}\right|}{p+\left|z_{m}\right|}, \frac{\rho}{p+\left|z_{m}\right|}\right\}<\infty .
$$

Hence $T$ is an automorphism of $\Lambda_{R}$ so $J T^{-1} J^{-1}$ is an automorphism of $\mathscr{F}_{R}$ and since $J T^{-1} J^{-1}\left(z^{n}\right)=r_{n} p^{n} \alpha_{n}$ it follows that $\left(r_{n} p^{n} \alpha_{n}\right)$ is a basis for $\mathscr{F}_{R}$ and since $r_{n} p^{n} \neq 0$, it follows that $\left(\alpha_{n}\right)$ is a basis for $\mathscr{F}_{R}$.

This completes the proof of the theorem.

CoRollary. A necessary condition for a linear Pincherle sequence $\left(\alpha_{n}\right)$ with zeros $\left(z_{n}\right)$ to be a basis for $\mathscr{F}_{R}$ is

$$
\varlimsup_{m}\left(\frac{1+\left|z_{m}\right|}{\left|z_{m}\right|}\right)^{1 / m} \quad\left\{\begin{array}{ll}
<\infty & \text { if } R=\infty \\
\leqq 1 & \text { if } R<\infty
\end{array} .\right.
$$

Proof. We apply $\left(C_{R}\right)$ and, in the second sup we always take $n=m$. The given condition is then easily derived.

REMARK. By taking other special values of $m$ and $n$ in $\left(C_{R}\right)$ we can easily obtain other necessary conditions. For example, if we take $m=0$ in the first sup, we immediately obtain condition (1.4) of [1]. These conditions will not be sufficient. For instance, the condition of the corollary is always satisfied if $z_{m}$ is constant. However, by Lemma 2.2 of [1], if this is so and $\left|z_{n}\right|<R$, then $\left(\alpha_{n}\right)$ will not be a basis. On the other hand, the condition of the corollary is strong enough to settle the question of when a linear Pincherle basis is proper.

TheOREm 2. Every linear Pincherle basis is proper.

Proof. In the proof of Theorem 1 it was shown that if a linear Pincherle sequence $\left(\alpha_{n}\right)$ is a basis for $\mathscr{F}_{R}$, then $\left(r_{n} p^{n} \alpha_{n}\right)$ is a proper basis in $\mathscr{F}_{R}$. Hence $\sum_{n} \xi_{n} \alpha_{n}$ converges iff

$$
\sum_{n=0}^{\infty} \frac{\xi_{n}}{r_{n} p^{n}} z^{n} \quad \text { converges in } \mathscr{F}_{R},
$$

which is equivalent, by the Cauchy-Hadamard formula to

$$
\varlimsup_{n}\left(\frac{\left|\xi_{n}\right|\left(p+\left|z_{n}\right|\right)}{\left|z_{n}\right|}\right)^{1 / n} \leqq \frac{1}{R}
$$


and, in view of the corollary, this is equivalent to $\overline{\lim }_{n}\left|\xi_{n}\right|^{1 / n} \leqq 1 / R$, i.e., that $\sum_{n} \xi_{n} z^{n}$ converges in $\mathscr{F}_{R}$.

REMARK. The above result shows that the sufficient condition given in Lemma 3.4 of [1] is also necessary. Alternatively, that lemma can be used, along with Theorem 1 to obtain Theorem 2 . This is done by observing that condition $\left(C_{R}\right)$ directly implies condition (3.11) of [1].

We turn now to the question of basis radius. A Pincherle sequence is said to have basis radius $R_{0}$ provided that it is a basis for $\mathscr{F}_{R}$ if and only if $0<R \leqq R_{0}$. This is slightly different, on the face of it, from the definition given by Arsove [1] who requires that the sequence be a basis for $\mathscr{F}_{R}$ whenever $R<R_{0}$ and fail to be a basis when $R>R_{0}$. The two statements are equivalent because it follows from general considerations that if a sequence is a basis for $\mathscr{F}_{R}$ whenever $R<R_{0}$, then it is a basis for $\mathscr{F}_{R_{0}}$.

Arsove [1] points out that a Pincherle sequence may fail to have a basis radius. The next theorem gives more or less complete information in the linear case.

THEOREM 3. Let $\left(\alpha_{n}\right)$ be a linear Pincherle sequence. Then $\left(\alpha_{n}\right)$ has a basis radius if and only if either $\left(C_{\infty}\right)$ fails or $\left(C_{R}\right)$ holds for all $R \leqq \infty$. In either case we have,

$$
R_{0}=\sup \left\{R: 0<R<\infty \text { and }\left(C_{R}\right) \text { holds }\right\} \text {. }
$$

Proof. If $\left(C_{R}\right)$ holds for all $R \leqq \infty$, then obviously $R_{0}=\infty$ and the given representation is valid. Suppose that $\left(C_{\infty}\right)$ fails and define $R_{0}$ as in the statement of the theorem. Then we have an increasing sequence $\left(R_{j}\right)$ of positive numbers which converges to $R_{0}$ and $\ni\left(C_{R_{j}}\right)$ holds for each $j$.

Suppose now that $R<R^{\prime}<\infty$ and $\left(C_{R^{\prime}}\right)$ holds. Then given $\rho<R$, we consider $\rho\left(R^{\prime} / R\right)<R^{\prime}$ so we have $\bar{\rho}$ from $\left(C_{R^{\prime}}\right)$. But then $\bar{\rho}\left(R / R^{\prime}\right)<R$ and the inequality in $\left(C_{R}\right)$ holds for $\rho, \bar{\rho}\left(R / R^{\prime}\right)$. Thus $\left(C_{R}\right)$ holds.

Thus we may conclude that for each $j$ and each $R<R_{j^{\prime}},\left(C_{R}\right)$ holds. This implies that $\left(C_{R}\right)$ holds for all $R<R_{0}$.

Finally, suppose $f \in \mathscr{F}_{R_{0}}$. For each $R<R_{0},\left(\alpha_{n}\right)$ is a basis for $\mathscr{F}_{R}$ and $f \in \mathscr{F}_{R}$. Hence we have a unique sequence, $\left(c_{n}^{R}\right)_{n}$ of scalars $\ni f=\sum c_{n}^{R} \alpha_{n}$ and the convergence is uniform on each closed disk of radius less than $R$. By the uniqueness, $\left(c_{n}^{R}\right)$ is independent of $R$ and this shows that $\left(\alpha_{n}\right)$ is a basis for $\mathscr{F}_{R_{0}}$. (This last argument is a specific proof of the equivalence of Arsove's definition of basis radius and the one given above.)

This completes the proof in one direction. The converse is obvious 
so the theorem is proved.

In Arsove's example showing that a linear Pincherle sequence can fail to have a basis radius, the sequence is a basis for $\mathscr{F}_{\infty}$ but not a basis for any $\mathscr{F}_{R}, 0<R<\infty$. We now give an example showing that for any $R_{0}$ with $0<R_{0}<\infty$, there is a linear Pincherle sequence which is a basis for $\mathscr{F}_{R}$ if and only if $R=\infty$ or $0<R \leqq R_{0}$.

EXAMPLE. Let $\left(z_{n}\right)$ be defined by

$$
z_{n}= \begin{cases}j^{4^{j}} & \text { for } n=2^{j}, j=1,2 \cdots \\ 1 & \text { otherwise }\end{cases}
$$

Then the linear Pincherle sequence $\left(\alpha_{n}\right)$ with zeros $\left(z_{n}\right)$ is a basis for $\mathscr{F}_{R}$ if and only if $R=\infty$ or $R \leqq 1$.

Proof. First we consider $R=\infty$. Fix $\rho<\infty$ and choose $\bar{\rho} \geqq \rho$. We may assume that $\rho>1$. Then

$$
\begin{aligned}
& \sup _{m \geqq 2} \frac{1}{\bar{\rho}^{m}} \sup _{n \geqq m} \frac{1+\left|z_{n}\right|}{\left|z_{m} \cdots z_{n}\right|} \rho^{n} \\
& \leqq 2 \sup _{j \geqq 0} \sup _{2^{j}<m 2^{j+1}} \frac{1}{\bar{\rho}^{m}} \sup _{n \geqq m} \frac{\rho^{n}}{\left|z_{m} \cdots z_{n-1}\right|} \\
& =2 \sup _{j \geq 0} \max \left\{\sup _{{ }_{2}{ }^{j<m<2 j+1}} \frac{1}{\bar{\rho}^{m}} \sup _{n \geqq m} \frac{\rho^{n}}{\left|\mathbf{z}_{m} \cdots z_{n-1}\right|}\right. \text {, } \\
& \left.\frac{1}{\bar{\rho}^{2 j+1}} \sup _{n \geqq 2^{j+1}} \frac{\rho^{n}}{\left|z_{2^{j+1}} \cdots z_{n-1}\right|}\right\} \\
& \leqq 2 \sup _{j \geqq 0} \max \left\{\sup _{2^{j} \sum_{j<2^{j+1}}} \frac{1}{\bar{\rho}^{m}} \sup _{n \geqq m} \frac{\rho^{n}}{\left|z_{m} \cdots z_{n-1}\right|}\right. \text {, } \\
& \left.\frac{\rho}{\bar{\rho}^{2 j+1}-1} \sup _{n \geq^{j+1}-1} \frac{\rho^{n}}{\left|z_{2^{j+1}-1} \cdots z_{n-1}\right|}\right\} \\
& \leqq 2 \rho \sup _{j \geqq 0} \sup _{2^{j}<m<2^{j+1}} \frac{1}{\bar{\rho}^{m}} \sup _{n \geqq m} \frac{\rho^{n}}{\left|z_{m} \cdots z_{n-1}\right|} \\
& =2 \rho \sup _{j \geqq 0} \sup _{2^{j}<m<2^{j+1}} \frac{1}{\bar{\rho}^{m}} \max \left\{\sup _{m \leqq n \leqq 2^{j+1}} \rho^{n},\right. \\
& \left.\frac{\rho^{2^{j+1}+1}}{(j+1)^{4 j+1}}, \sup _{n>2^{j+1}+1} \frac{\rho^{n}}{\left|z_{m} \cdots z_{n-1}\right|}\right\} .
\end{aligned}
$$

Now, if $j \geqq \rho-1$, the expression after the first sup is dominated by

$$
\sup _{{ }_{2}^{j}<m<2^{j+1}} \frac{1}{\bar{\rho}^{m}} \max \left\{\rho^{2^{j+1}}, \sup _{i>j} \frac{\rho^{4 i+1}}{i^{4^{i}}}\right\} \leqq \sup _{2^{j}<m<2^{j+1}} \frac{\rho^{2^{j+1}}}{\bar{\rho}^{m}} \leqq 1,
$$

for $j$ sufficiently large. This shows that the quantity in $\left(C_{\infty}\right)$ is dominated by $2 \rho$ for $m$ sufficiently large and so it remains to show that for each $m$, 


$$
\sup _{n \geqq m} \frac{\rho^{n}}{\left|z_{m} \cdots z_{n-1}\right|}<\infty .
$$

But, given $m$, for $n$ sufficiently large, we can take $2^{j}<n \leqq 2^{j+1}$ and obtain,

$$
\frac{\rho^{n}}{\left|z_{m} \cdots z_{n-1}\right|} \leqq \frac{\rho_{1}^{2^{j+1}}}{j^{4 j}}<1 \text { for } j \text { sufficiently large }
$$

Hence by Theorem $1,\left(\alpha_{n}\right)$ is a basis for $\mathscr{F}_{\infty}$.

For $R \leqq 1$, we fix $\rho<R$ and choose $\bar{\rho}$ with $\rho \leqq \bar{\rho}<R$ and we have

$$
\begin{aligned}
& \sup _{m} \frac{1}{\bar{\rho}^{m}} \sup _{n \geqq m} \frac{\left(1+\left|z_{n}\right|\right) \rho^{n}}{\left|z_{m} \cdots z_{n-1}\right|} \leqq 2 \sup _{m} \frac{1}{\bar{\rho}^{m}} \sup _{n \geqq m} \frac{\rho^{n}}{\left|z_{m} \cdots z_{n-1}\right|} \\
& =2 \sup _{m} \frac{1}{\bar{\rho}^{m}} \sup _{n \geqq m} \rho^{n}=2 \sup _{m}\left(\frac{\rho}{\bar{\rho}}\right)^{m}=2,
\end{aligned}
$$

so $\left(\alpha_{n}\right)$ is a basis for $\mathscr{F}_{R}, R \leqq 1$.

Finally, if $R>1$ we can choose $\rho<R, \rho>R^{2 / 3}$. Then for any $\bar{\rho}<R$, we choose $m=2^{j-1}+1, n=2^{j}$ to obtain,

$$
\begin{gathered}
\sup _{m} \sup _{n \geqq m} \frac{1+\left|z_{n}\right|}{\left|z_{m} \cdots z_{n}\right|} \rho^{n} \frac{1}{\bar{\rho}^{m}} \geqq \sup _{j} \frac{1+\left|z_{2^{j}}\right|}{\left|z_{2^{j-1}+1} \cdots z_{2^{j}}\right|} R^{2^{j-2} 2^{j-1}-1}\left(\frac{\rho}{R}\right)^{2^{j}} \\
\geqq \sup _{j}\left[\left(\frac{\rho}{R}\right)^{2^{j} 2_{2 j-1}{ }^{j-1}} R\right]^{2^{j-1-1}} \geqq \sup _{j}\left[\left(\frac{\rho}{R}\right)^{3} R\right]^{2^{j-1-1}}=\infty,
\end{gathered}
$$

so by Theorem $1,\left(\alpha_{n}\right)$ is not a basis for $\mathscr{F}_{R}$.

This completes the proof of the example which is a special case of the statement we made before the example. For the general case, we simply observe that from Theorem 1 it follows immediately that if $\left(\alpha_{n}\right)$ is a linear Pincherle sequence which is a basis for $\mathscr{F}_{R}$, $0<R<\infty$ with zeros, $\left(z_{n}\right)$, then for any $a>0$, the linear Pincherle sequence obtained by taking, as zeros, the sequence $\left(z_{n} / a\right)$ is a basis for $\mathscr{F}_{a R}$.

Finally we observe that in the above example, if $n=2^{j}$, then

$$
\left|z_{0} \cdots z_{n-1}\right|^{1 / n} \geqq j^{2^{j-1}}
$$

so that for any positive number $p$ we have

$$
\varlimsup_{n} \frac{\left|z_{0} \cdots z_{n-1}\right|^{1 / n}}{n^{p}}=\infty .
$$

This shows that the sufficient condition of Arsove ([1], Theorem 4.3) is not necessary for a linear Pincherle sequence to be a basis for $\mathscr{F}_{\infty}$. 
Remarks added in proof.

1. It has recently been shown by L. Crone and W. B. Robinson (Studia Math. 52 (1974) 203-207) that any two regular bases in a nuclear Fréchet space are equivalent and thus we can drop the requirement in the above Lemma that the two bases are both of type $D_{1}$ or of type $D_{2}$. This considerably simplifies the proof of Theorem 1.

2. Using a recent result of Nguyen Thanh Van (Ann. Inst. Fourier, $22: 2$, 1972, pp. 187-190) it is possible to prove Theorem 2 without assuming that the basis is linear. There are many additional applications of this fact including an improved version of Theorem 3.

\section{REFERENCES}

1. M. G. Arsove, On the behavior of Pincherle basis functions, Pacific J. Math., 44 1, (1973), 13-31.

2. C. Bessaga, Some remartes on Dragilev's theorem, Studia Math., 31 (1968), 307-318.

3. M. M. Dragilev, On regular bases in nuclear spaces, Amer. Math. Soc. Transl., (2), 93 (1970), 61-82.

Received July 6, 1973. This research was partially supported by the National Science Foundation.

Clarkson College of Technology 



\section{PACIFIC JOURNAL OF MATHEMATICS}

\section{EDITORS}

RICHARD ARENS (Managing Editor)

University of California

Los Angeles, California 90024

\section{R. A. Beaumont \\ University of Washington \\ Seattle, Washington 98105}

\section{J. DugundJI}

Department of Mathematics

University of Southern California

Los Angeles, California 90007

D. Gilbarg and J. Milgram

Stanford University

Stanford, California 94305

\section{ASSOCIATE EDITORS}
E. F. BECKENBACH
B. H. NeumanN
F. WOLF
K. YOSHIDA

\section{SUPPORTING INSTITUTIONS}

UNIVERSITY OF BRITISH COLUMBIA
CALIFORNIA INSTITUTE OF TECHNOLOGY
UNIVERSITY OF CALIFORNIA
MONTANA STATE UNIVERSITY
UNIVERSITY OF NEVADA
NEW MEXICO STATE UNIVERSITY
OREGON STATE UNIVERSITY
UNIVERSITY OF OREGON
OSAKA UNIVERSITY

UNIVERSITY OF BRITISH COLUMBIA

UNIVERSITY OF CALIFORNIA

MONTANA STATE UNIVERSITY

NEW MEXICO STATE UNIVERSITY

OREGON STATE UNIVERSITY

OSAKA UNIVERSITY

\author{
UNIVERSITY OF SOUTHERN CALIFORNIA \\ STANFORD UNIVERSITY \\ UNIVERSITY OF TOKYO \\ UNIVERSITY OF UTAH \\ WASHINGTON STATE UNIVERSITY \\ UNIVERSITY OF WASHINGTON \\ AMERICAN MATHEMATICAL SOCIETY \\ NAVAL WEAPONS CENTER
}

The Supporting Institutions listed above contribute to the cost of publication of this Journal, but they are not owners or publishers and have no responsibility for its content or policies.

Mathematical papers intended for publication in the Pacific Journal of Mathematics should be in typed form or offset-reproduced, (not dittoed), double spaced with large margins. Underline Greek letters in red, German in green, and script in blue. The first paragraph or two must be capable of being used separately as a synopsis of the entire paper. Items of the bibliography should not be cited there unless absolutely necessary, in which case they must be identified by author and Journal, rather than by item number. Manuscripts, in triplicate, may be sent to any one of the editors. Please classify according to the scheme of Math. Reviews, Index to Vol. 39. All other communications should be addressed to the managing editor, or Elaine Barth, University of California, Los Angeles, California, 90024.

The Pacific Journal of Mathematics expects the author's institution to pay page charges, and reserves the right to delay publication for nonpayment of charges in case of financial emergency.

100 reprints are provided free for each article, only if page charges have been substantially paid. Additional copies may be obtained at cost in multiples of 50 .

The Pacific Journal of Mathematics is issued monthly as of January 1966. Regular subscription rate: $\$ 72.00$ a year (6 Vols., 12 issues). Special rate: $\$ 36.00$ a year to individual members of supporting institutions.

Subscriptions, orders for back numbers, and changes of address should be sent to Pacific Journal of Mathematics, 103 Highland Boulevard, Berkeley, California, 94708.

PUBLISHED BY PACIFIC JOURNAL OF MATHEMATICS, A NON-PROFIT CORPORATION

Printed at Kokusai Bunken Insatsusha (International Academic Printing Co., Ltd.), 270, 3-chome Totsuka-cho, Shinjuku-ku, Tokyo 160, Japan.

Copyright (C) 1973 by Pacific Journal of Mathematics Manufactured and first issued in Japan 


\section{Pacific Journal of Mathematics \\ Vol. 55, No. $2 \quad$ October, 1974}

Walter Allegretto, On the equivalence of two types of oscillation for elliptic

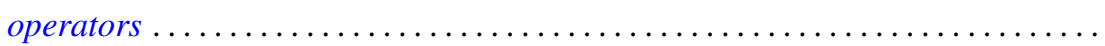

Edward Arthur Bertram, A density theorem on the number of conjugacy classes in

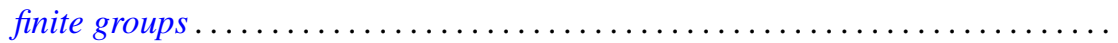

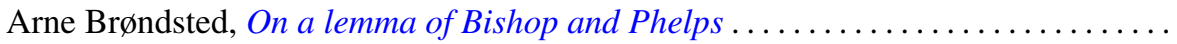

Jacob Burbea, Total positivity and reproducing kernels ..................

Ed Dubinsky, Linear Pincherle sequences . . . . . . . . . . . . . . . . . .

Benny Dan Evans, Cyclic amalgamations of residually finite groups .............

361

Barry J. Gardner and Patrick Noble Stewart, A "going down" theorem for certain

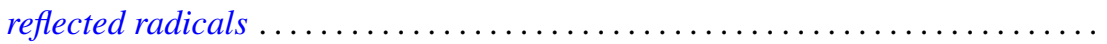

381

Jonathan Light Gross and Thomas William Tucker, Quotients of complete graphs:

revisiting the Heawood map-coloring problem ....................

Sav Roman Harasymiv, Groups of matrices acting on distribution spaces .........

Robert Winship Heath and David John Lutzer, Dugundji extension theorems for

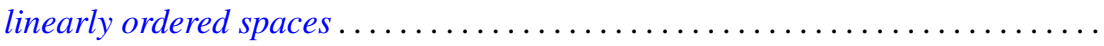

Chung-Wu Ho, Deforming p. l. homeomorphisms on a convex polygonal

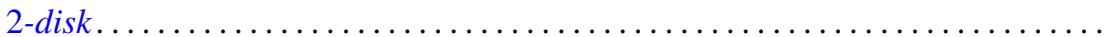

Richard Earl Hodel, Metrizability of topological spaces .................

Wilfried Imrich and Mark E. Watkins, On graphical regular representations of

cyclic extensions of groups .......................... 461

Jozef Krasinkiewicz, Remark on mappings not raising dimension of curves ..... . 479

Melven Robert Krom, Infinite games and special Baire space extensions . . . . . . 483

S. Leela, Stability of measure differential equations . . . . . . . . . . . . . . . . 489

M. H. Lim, Linear transformations on symmetric spaces . . . . . . . . . . . . . . . 499

Teng-Sun Liu, Arnoud C. M. van Rooij and Ju-Kwei Wang, On some group algebra modules related to Wiener's algebra $M_{1} \ldots \ldots \ldots \ldots \ldots \ldots \ldots \ldots \ldots \ldots \ldots$

Dale Wayne Myers, The back-and-forth isomorphism construction ............ 521

Donovan Harold Van Osdol, Extensions of sheaves of commutative algebras by

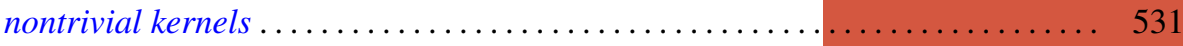

Alan Rahilly, Generalized Hall planes of even order ................... 543

Joylyn Newberry Reed, On completeness and semicompleteness of first countable

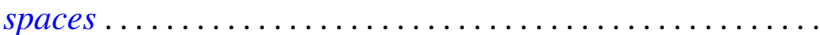

Alan Schwartz, Generalized convolutions and positive definite functions associated

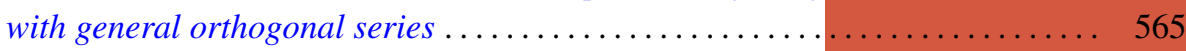

Thomas Jerome Scott, Monotonic permutations of chains . . . . . . . . . . . 583

Eivind Stensholt, An application of Steinberg's construction of twisted groups .... 595

Yasuji Takeuchi, On strongly radicial extensions . . . . ................. 619

William P. Ziemer, Some remarks on harmonic measure in space . . . . . . . . . . 629

John Grant, Corrections to: “Automorphisms definable by formulas” . . . . . . . . 639

Peter Michael Rosenthal, Corrections to: "On an inversion for the general

Mehler-Fock transform pair" ......................... 640

Carl Clifton Faith, Corrections to: "When are proper cyclics injective” . . . . . . 640 